\title{
Reflexões sobre os conceitos de responsabilidade e culpa na obra de Karl Jaspers e sobre sua aplicabilidade à ditadura de 1976-1983 na Argentina
}

Bruno Groppo*

Resumo: $\mathrm{O}$ artigo analisa, numa primeira parte, os conceitos de responsabilidade e culpa desenvolvidos pelo filósofo Karl Jaspers, em 1946, em seu livro Die deutsche Schuld (A culpabilidade alemã) sobre os crimes cometidos pela Alemanha nazista. Convidando seus compatriotas a um exame de consciência sobre esta questão, Jaspers permaneceu então uma voz solitária em um país que aspirava a esquecer especialmente o passado nazista. A partir dos anos 1960, no entanto, a República Federal da Alemanha comprometeu-se com este trabalho de memória, que continua até os dias atuais. $\mathrm{Na}$ segunda parte, o artigo analisa a possibilidade de aplicar os conceitos de Jaspers sobre os diferentes tipos de culpa e responsabilidade - penal, política, moral, metafísica - à sociedade argentina durante e depois dos anos da ditadura militar de 1976-1983.

Palavras-chave: Nazismo. Jaspers. Culpabilidade. Memória. Argentina.

* Pesquisador do Centre National de la Recherche Scientifique, Paris e do Centre d'Histoire Sociale du XXe Siècle, Université de Paris I - Panthéon Sorbonne. Em 2011-2012, foi professor visitante (bolsa CAPES) na Universidade Federal Fluminense (Niterói, Rio de Janeiro). E-mail: brunogroppo@yahoo.fr; bruno. groppo@univ-parisI.fr. Endereço para correspondência: CHS Xxe Siècle - 9, rue Malher - 75181 Paris cedex 04 (France). Tradução de Patrícia C.R. Reuillard. 
Reflexões sobre os conceitos de responsabilidade e culpa...

\section{Introdução}

A identidade de uma sociedade, assim como a de um indivíduo, define-se, em larga medida, pelo trabalho duplo da memória e do esquecimento. Em outras palavras, a identidade social constitui-se tanto com o que foi transmitido pela memória quanto com o que foi apagado, voluntária ou involuntariamente, pelo esquecimento: ela resulta de uma seleção, que conserva e transmite certos aspectos do passado, enquanto descarta outros, particularmente as experiências traumáticas cuja evocação provoca sofrimento, vergonha ou malestar. Enquanto construção social, a identidade é uma realidade em perpétua construção, que se modifica e se transforma sem cessar. Trata-se, portanto, de um conceito problemático, cujo conteúdo e contornos exatos são difíceis de definir. Em toda sociedade, coexistem várias identidades e várias memórias coletivas, que correspondem aos diferentes grupos que a compõem. Elas concorrem entre si e, com frequência, entram em conflito. Falar da identidade de uma sociedade ou de uma nação tem sentido apenas para designar o espaço simbólico para onde convergem e se sobrepõem, parcialmente, suas diferentes identidades sociais.

Certos acontecimentos e experiências deixam uma marca particularmente profunda na memória coletiva, como as experiências traumáticas de guerras ou ditaduras, que permanecem gravadas como cicatrizes no corpo social, deixando um rastro de memórias não somente diferentes, mas, quase sempre, irredutivelmente opostas. Um regime de terror, como o da Alemanha nazista, não deixa nada intacto, já que o terror modifica o comportamento de cada indivíduo em profundidade, obriga-o a fazer escolhas dramáticas - que vão da colaboração ativa à resistência aberta, passando por toda uma série de nuances intermediárias - e, de maneira geral, destrói os laços sociais. $\mathrm{O}$ indivíduo que vivencia uma situação assim fica para sempre marcado por ela. Quando um regime desse tipo desaparece, surge, inevitavelmente, o problema das responsabilidades, sobretudo quando crimes muito graves foram cometidos. Cada sociedade resolve isso a seu modo, e não há um modelo que sirva de referência universal. Determinar as responsabilidades e punir os culpados pelos crimes é uma tarefa extremamente árdua, e as soluções adotadas raramente 
são satisfatórias do ponto de vista da justiça abstrata, pois a exigência de justiça é, muitas vezes, deliberadamente sacrificada em nome de uma hipotética "reconciliação nacional" ou de outros imperativos, e a impunidade em geral acaba vencendo. Por exemplo, na Alemanha pós-Guerra, inúmeros responsáveis nazistas, culpados por crimes de guerra ou por crimes contra a humanidade, não foram perseguidos e puderam seguir tranquilamente suas trajetórias; na Rússia, após o fim do regime comunista, nem um único responsável por crimes da época stalinista foi julgado; na Argentina, onde alguns responsáveis pela última ditadura militar haviam sido julgados e condenados, acabouse dando impunidade a todos os culpados, inclusive aos autores de crimes contra a humanidade (o único crime não beneficiado pela anistia foi o do sequestro de crianças) devido a múltiplas chantagens e pressões. A lista não é exaustiva. Porém, também constata-se que não se pode impor a uma sociedade, por decreto, como na Argentina, ou por outros meios, um esquecimento definitivo dos crimes. A memória é tenaz, e cedo ou tarde chega o momento em que uma sociedade precisa prestar contas com seu passado.

Este estudo analisa o caso da Alemanha e, mais especificamente, a questão da responsabilidade nos crimes cometidos pelo regime nazista. Por seu caráter extremo, o exemplo deste país tem valor de paradigma e permite mostrar nitidamente os dilemas e as alternativas de uma sociedade confrontada com um passado criminoso. Escolhi como fio condutor a reflexão do filósofo alemão Karl Jaspers sobre a culpa alemã pelos crimes nazistas ${ }^{1}$. Formulada imediatamente após a Guerra e tendo permanecido isolada, essa reflexão levanta problemas que dizem respeito não somente à Alemanha, mas também a outras sociedades que tiveram regimes criminosos. $\mathrm{Na}$ segunda parte do artigo, tentarei ver como ela poderia se aplicar à situação da Argentina após a última ditadura.

\section{O contexto histórico}

Relembro brevemente, de início, o contexto histórico da reflexão de Jaspers. Três circunstâncias tornavam particularmente difícil, na Alemanha de 1945, a confrontação com o passado nazista. Em 
Reflexões sobre os conceitos de responsabilidade e culpa...

primeiro lugar, o caráter sem precedentes dos crimes nazistas e o fato de que um número significativo de alemães havia participado diretamente ou estava associado a eles de algum modo. Era o caso, em particular, do mais terrível desses crimes, o extermínio dos judeus da Europa. Antes disso houvera outros genocídios, como o das populações indígenas das Américas ou o dos armênios, mas jamais um Estado moderno empreendera um projeto como este de destruição sistemática de todo um povo, empregando todos os recursos técnicos e materiais disponíveis para executá-lo: desse ponto de vista, o extermínio dos judeus representa algo único e pode ser comparado apenas parcialmente aos genocídios anteriores ou a outros massacres em massa. O caráter "industrial" do assassinato em massa executado pelos nazistas, nas verdadeiras fábricas da morte que eram os campos de extermínio, tornara necessária a participação não somente de especialistas em assassinato, mas também o envolvimento de um grande número de pessoas trabalhando em diferentes órgãos e empresas - fossem as ferrovias, engrenagem essencial da máquina de destruição, ou as empresas que produziam os fornos crematórios ou o Zyklon B utilizado nas câmaras de gás. A responsabilidade por esse crime não se limitava, portanto, aos executores diretos, mas estendia-se a um círculo muito mais amplo de indivíduos.

A segunda circunstância que dificultava a confrontação com o passado residia no fato de que grande parte da população alemã havia dado seu apoio, até o fim, ao regime nazista e se identificara com seu líder. De fato, a ditadura nazista havia angariado uma ampla adesão da sociedade. Quando chegou ao poder, o partido nazista era a principal força política e eleitoral da Alemanha, e Hitler contava com a confiança de milhões de eleitores. Fora então voluntariamente que milhões de alemães haviam dado as costas à democracia, considerada como responsável por todas suas mazelas, e caído na ditadura. Os que tentaram resistir, e povoaram os campos de concentração e as prisões da Alemanha hitlerista, eram uma minoria, certamente heroica, mas uma minoria. Em suma, os nazistas não eram monstros vindos de fora, mas um produto e um espelho da sociedade alemã.

A terceira razão, por fim, era que a população não havia participado, fosse como fosse, de sua própria libertação ${ }^{2}$. Esta veio do exterior, e a eliminação do regime nazista foi resultado exclusivo 
da derrota militar infligida por exércitos estrangeiros, não de uma revolta popular ou de uma guerra civil. Isso explica o caráter ambíguo do dia 8 de maio de 1945, na Alemanha, data que marca o fim da Guerra, e que, para a população, significava a libertação e, ao mesmo tempo, a derrota.

Essas circunstâncias explicam a reticência, a hesitação e, em última análise, a recusa de grande parte da população a simplesmente levantar o problema da culpa. Quando o mundo inteiro apontava um dedo acusador para a Alemanha, que passou a ser uma espécie de pária entre as nações, a tendência da população alemã era se furtar a esse problema e se considerar mais como vítima (dos bombardeios, das expulsões, da ocupação estrangeira, da fome) do que como responsável pelos sofrimentos infligidos a outros povos. Jaspers descreve esse estado de espírito:

Vivemos desamparados. Uma grande parte de nossa população vive em um desamparo tão grande, tão imediato, que parece ter se tornado indiferente a essas discussões. O que lhe interessa é o que diminui a miséria, o que proporciona trabalho e pão, moradia, calor. O horizonte ficou estreito. Ela não gosta de ouvir falar de culpa, do passado; não é afetada pela história mundial. Só quer parar de sofrer, sair da penúria, quer viver, mas não refletir. É como se, após um sofrimento tão terrível, tivéssemos de ser recompensados, ou, pelo menos, consolados, mas não tomados, ainda por cima, pela culpa (JASPERS, 1990, p. 43). ${ }^{3}$

\section{Uma reflexão à contracorrente}

Ao interrogar-se sobre a questão da culpa e das responsabilidades, Jaspers situa-se, portanto, na contracorrente da opinião majoritária, mas está convencido, como alemão, de que isso é absolutamente essencial: 
Reflexões sobre os conceitos de responsabilidade e culpa...

Nós, os alemães, temos o dever, sem exceção, de encarar o problema de nossa culpa e de tirar as consequências disso. Nossa dignidade humana nos obriga a isso [...] nossa própria vida [...] só poderá ser digna se formos sinceros com nós mesmos. Os outros levantam a questão de nossa culpa, mas, mais do que isso, é uma questão que nós próprios nos fazemos. A resposta que dermos a ela em nosso íntimo fundamentará nossa consciência atual do ser e de nós mesmos. É uma questão vital para a alma alemã. ${ }^{4}$ (JASPERS, 1990, p. 44).

Segundo o filósofo, questionar-se é a única maneira de se libertar do peso na consciência (JASPERS, 1990, p. 44) .

Jaspers distingue quatro tipos de culpa: criminal, política, moral e metafísica.

A culpa criminal diz respeito aos crimes, “[...] atos objetivamente determinados que transgredem leis unívocas", e tem a ver com o tribunal, que "[...] estabelece os fatos de acordo com um procedimento formal, aplicando-lhes as leis" (JASPERS, 1990, p. 45). Somente os indivíduos responsáveis por esses atos podem ser culpados de crimes e, por essa razão, serem punidos pelos tribunais. Falar de culpa criminal de todo um povo não tem nenhum sentido.

A culpa política significa que os cidadãos de um Estado são responsáveis e devem "[...] assumir as consequências dos atos realizados por esse Estado” (JASPERS, 1990, p. 46), sobretudo se o tiverem apoiado. Neste caso, Jaspers salienta que "[...] se toda decência e toda boa fé foram destruídas na política do Estado alemão, isso deve ter resultado, entre outros, do comportamento da maioria da população alemã. Um povo é responsável pela política de seu governo" (JASPERS, 1990, p. 71) ${ }^{6}$. Assim, os alemães precisam responder coletivamente pelos crimes cometidos em nome do Estado alemão. "Nós carregamos a responsabilidade política de nosso regime, de seus atos, do desencadeamento da guerra em uma situação histórica mundial como esta, e do caráter do líder que escolhemos" (JASPERS, 1990, p. 87). Todavia, isso "[...] não significa que cada cidadão individualmente seja culpado criminal e moralmente pelos crimes cometidos em nome do Estado" (JASPERS, 1990, p. 47). Jaspers esclarece: 
Nós, alemães, devemos responder pelos atentados atrozes cometidos contra nós por alemães, ou por aqueles aos quais nós escapamos por milagre? Sim, na medida em que toleramos que tal regime se estabelecesse no nosso país. Não, na medida em que muitos de nós éramos em nosso íntimo adversários de todo esse mal, e que nenhum ato, nenhuma complacência de nossa parte levam a reconhecer a culpa moral. Sermos responsabilizados por tudo isso não significa nos declararmos moralmente culpados. Há, portanto, forçosamente uma culpa coletiva enquanto responsabilidade política dos membros de um Estado, mas isso não acarreta nem uma culpa coletiva moral ou metafísica, nem uma culpa coletiva criminal (JASPERS, 1990, p. 72) 7 .

O terceiro tipo de culpa é a culpa moral. Ela significa que todo indivíduo é moralmente responsável por seus atos e que todo ato pode ser julgado moralmente: "[...] um crime continua sendo um crime mesmo que tenha sido ordenado". Assim como a culpa criminal, a culpa moral só diz respeito a indivíduos. Conforme Jaspers, ela:

[...] subsiste em todos aqueles que admitem a consciência e o arrependimento. São culpados moralmente os seres capazes de expiação, aqueles que sabiam ou que podiam saber, e que apesar disso tomaram caminhos que sabiam errados, quando fazem um exame de consciência. Por comodidade, dissimularam a si mesmos o que se passava; ou se deixaram aturdir e seduzir; ou se deixaram comprar com vantagens pessoais; ou então obedeceram por medo (JASPERS, 1990, p. 74).

A culpa metafísica, por fim, significa que

[...] entre os homens, por serem homens, existe uma solidariedade que torna cada indivíduo corresponsável por toda injustiça e por todo mal cometido no mundo, especialmente por crimes cometidos em sua presença, ou com seu conhecimento (JASPERS, 1990, p. 47) ${ }^{8}$. 
A parte mais instigante da reflexão de Jaspers é, provavelmente, aquela sobre a responsabilidade moral. O filósofo interroga-se, especialmente, sobre a questão da consciência limpa no crime e no mal, de que tantos alemães deram provas, e sobre os mecanismos que tornaram possível essa consciência limpa (principalmente a concepção nacional cega que identificava sem reservas Estado nazista e nação, assim como a sede de obediência e de submissão). Ele lembra que o patriotismo não pode em caso algum desculpar o crime. De fato:

[...] a pátria não é um objetivo em si; ela se torna até mesmo perniciosa se um regime destrói o que faz a essência da Alemanha. O dever para com a pátria não acarretava absolutamente, para quem quisesse permanecer coerente consigo mesmo, a obrigação de obedecer a Hitler e de admitir como evidente que a Alemanha, mesmo hitlerista, devia absolutamente ganhar a guerra. Foi nisso que a consciência mentiu. Não se trata de uma culpa pura e simples, mas de uma trágica confusão de que foi vítima grande parte da juventude, sem se dar conta. [...] Foi assim que se viveu esta coisa surpreendente: apesar de todo o mal, as pessoas continuaram a se identificar com o exército e com o Estado. Este valor absoluto atribuído a uma concepção nacional cega [...] fazia com que, mesmo quando se tinha a consciência limpa, se fosse moralmente culpado. (JASPERS, 1990, p. 75).

Jaspers distingue diferentes níveis de culpa moral: por exemplo a passividade, que consiste no fato de não se ter aproveitado as oportunidades para resistir e para diminuir a injustiça, pois " [...] mesmo quando se submetiam por impotência, restava sempre uma margem de manobra para uma atividade, certamente não isenta de perigo, mas que, com prudência, podia ser eficaz" (JASPERS, 1990, p. 79); o conformismo, acerca do qual Jaspers observa que "[...] ninguém poderá se justificar completamente por ter agido assim, considerando sobretudo que muitos alemães recusaram-se, na verdade, a realizar tais atos de submissão e assumiram as consequências dessa recusa" (JASPERS, 1990, p. 79). 
A culpa que se deve assumir não diz respeito apenas aos contemporâneos:

Devemos assumir a culpa de nossos pais. As condições espirituais de vida na Alemanha eram tais que permitiram o advento de um regime como este; disso todos juntos somos culpados. O que não acarreta absolutamente a obrigação de admitir que 'o mundo do pensamento alemão', 'o pensamento alemão do passado' tenham originado os crimes do nacional-socialismo. Mas isso significa que, na tradição de nosso povo, esconde-se algo poderoso, ameaçador, que tende a destruir nossa vida moral (JASPERS, 1990, p. 88).

\section{Amnésia e despertar da sociedade alemã}

Karl Jaspers não foi o único na Alemanha a levantar, logo após a Guerra, o problema da responsabilidade e da culpa pelos crimes do nazismo e a catástrofe que ele provocara. No lado ocidental do país, que se tornou em seguida a República Federal da Alemanha (RFA), o problema foi discutido publicamente por outras grandes personalidades, como Friedrich Meinecke, Romano Guardini, Alfred Weber, Ernst Wiechert e Günther Weisenborn?. Todavia, eram as vozes de uma minoria, isolada em meio a um silêncio quase geral. A tendência dominante foi esquecer o passado, refugiando-se na amnésia individual e coletiva ${ }^{10}$. Potentes reflexos de autoproteção funcionaram como um escudo ou como um muro de separação em relação a um passado que era pura e simplesmente negado, como se jamais houvesse existido. Concentrando-se em seus próprios sofrimentos, a população alemã praticou um esquecimento seletivo, que não a impedia de se lembrar perfeitamente dos aspectos do passado que não implicavam responsabilidade pessoal. Essa atitude, que poderia ser definida como esquizofrênica, foi assim descrita por Ralph Giordano: 
Reflexões sobre os conceitos de responsabilidade e culpa...

Excelente memória para todas as áreas da vida privada e da vida política entre 1933 e o fim da Guerra, nas quais se presume não haver nada de perturbador. Falta de memória em relação a todos os acontecimentos marcados por desprazer, vergonha ou sentimentos de culpa. Portanto, seleciona-se com precisão o que deve ser esquecido e o que não deve. Esquecidos os campos de concentração e o Holocausto. Não esquecidos os atos de violência contra alemães e a guerra aérea. E quando realmente não se tem saída, utiliza-se o princípio da compensação: a expulsão [da população alemã da Tchecoslováquia, Polônia, etc. após a guerra ${ }^{11}$ contra Auschwitz (GIORDANO, 1990, p. 36).

Raros eram os alemães, excetuando a minoria diretamente perseguida pelo regime, dispostos a admitir que sabiam, ao menos em parte, do que se passava nos campos de concentração, tão numerosos na Alemanha, ou do extermínio dos judeus, dos massacres em grande escala perpetrados pelas tropas alemãs - não somente pelas tropas $S S$ e outros comandos especializados de matadores, mas pela própria Wehrmacht - na Polônia e na URSS, do tratamento desumano infligido aos prisioneiros de guerra soviéticos (GIORDANO, 1990) ${ }^{12}$. Uma vez terminada a desnazificação, comandada pelas autoridades de ocupação que se revelou, aliás, pouco eficaz, o nazismo foi objeto, até o fim dos anos 1960, de um silêncio coletivo e de uma amnésia generalizada (BENZ, 1994, p. 12-24) ${ }^{13}$. Alexander e Margarethe Mitscherlich insistiram, em um livro muito conhecido, sobre a incapacidade da sociedade ocidental alemã de deixar para trás o nazismo e a perda do Führer, "objeto de amor" com o qual milhões de alemães se haviam identificado (MITSCHERLICH, A.; MITSCHERLICH, M., 1972) ${ }^{14}$. Um estudo de Pierre-Yves Gaudard também ressalta essa incapacidade para assumir "o fardo da memória”, pesado demais na Alemanha ocidental do pós-Guerra (GAUDARD, 1997) ${ }^{15}$.

Essa tendência foi posteriormente reforçada pela Guerra Fria e pelo anticomunismo. O antitotalitarismo, isto é, a dupla rejeição ao nazismo e ao comunismo foi o fundamento do consenso constitucional na RFA, mas, durante a Guerra Fria, o segundo componente, 
o anticomunismo, sobrepujou rapidamente o primeiro. O novo clima político, dominado pelo confronto Leste-Oeste, permitia recuperar uma parte da ideologia nazista, ou seja, a hostilidade ao comunismo e à União Soviética, salienta Wolfgang Benz (BENZ, 1994, p. 23) ${ }^{16}$. Era possível, por exemplo, lembrar da Guerra contra a URSS não como uma guerra de extermínio, mas como uma guerra "comum" e legítima contra o comunismo e a ameaça que ele representava para a Europa. Os sucessivos governos alemães ocidentais encorajaram a tendência ao esquecimento e à amnésia. Durante muito tempo, o período 1933-1945 foi deixado entre parênteses e não se procurou lançar luz sobre o papel e as responsabilidades de cada um durante o Terceiro Reich. Desse modo, muitos ex-nazistas puderam continuar tranquilamente suas carreiras, inclusive em altos postos públicos, sem precisarem prestar contas ou serem perturbados. Essa amnésia coletiva era uma forma de anistia, sobretudo de autoanistia. $\mathrm{Na}$ perspectiva dos sucessivos governos conservadores, até os anos 1960, o esquecimento e o eliminar da consciência ("Verdrängung") faziam parte de uma estratégia que visava a integrar o novo sistema político os milhões de ex-nazistas. Segundo Régine Robin:

[...] a sacada de gênio de Konrad Adenauer foi limitar ao máximo a desnazificação por meio de uma série de artigos constitucionais e leis de anistia, de modo a reintegrar na vida nacional todos aqueles que se tinham comprometido com o nacional-socialismo em graus diversos e, ao mesmo tempo, devolver o orgulho aos alemães apartados da humanidade, afirmando que o povo alemão havia sofrido muito e que também ele era vítima (ROBIN, 2001, p. 41).

A política do esquecimento, de um lado, e o anticomunismo, do outro, permitiram que os ex-nazistas - o partido nazista tivera mais de oito milhões de partidários - aceitassem uma democracia que, a seu ver, tinha pelo menos a vantagem de ser hostil ao comunismo. Como ainda observa Régine Robin:

[...] era preciso acostumar-se com a democracia antes da justiça e antes da memória coletiva. As duas noções pareciam 
Reflexões sobre os conceitos de responsabilidade e culpa...

incompatíveis de imediato. Que os tribunais se ocupassem dos verdadeiros criminosos, mas que se parasse de perseguir os outros, isto é, a imensa maioria da população. Era preciso "deixar os companheiros de estrada em paz" (ROBIN, 2001, p. 42).

Essa estratégia de integração foi eficaz graças também a uma conjuntura econômica de crescimento prolongado, após os difíceis anos iniciais de reconstrução. A vontade de esquecer o passado nazista incitou a população alemã ocidental a concentrar suas energias na reconstrução da economia e na conquista de um certo bem-estar.

Acompanhada e encorajada pelos governos conservadores, a amnésia coletiva predominou até a década de 1960, quando vários acontecimentos contribuíram para reativar a memória: o processo de Adolf Eichmann, um dos organizadores da "solução final", em Jerusalém, seguido de outros processos contra guardas do campo de Auschwitz, na RFA; a chegada à idade adulta de uma nova geração, nascida após a Guerra, desejosa de conhecer a verdade sobre o passado e de romper com o silêncio infligido pelos pais ${ }^{17}$; a intensa efervescência cultural e política dessa década; uma maior sensibilidade ao problema do Holocausto; e a formação de uma nova geração de historiadores, mais atenta à história social e muito menos marcada pelo espírito nacionalista que as gerações anteriores. Assistiu-se também ao retorno progressivo de um passado que se pretendeu eliminar da consciência. Certos gestos simbólicos, como o do chanceler Willy Brandt ajoelhando-se no Gueto de Varsóvia, diante do memorial aos heróis do levante, reforçaram esse processo de restabelecimento da memória. A própria eleição de Brandt como chanceler era sintoma de uma mudança considerável, já que era um ex-resistente e exilado que chegava pela primeira vez à magistratura suprema. Só sua presença já lembrava os doze anos do nazismo e o fato de que também alemães haviam resistido a Hitler.

A partir dos anos 1960, a sociedade alemã ocidental confrontou-se cada vez mais ativamente com esse passado trágico que ela quisera esquecer, e pode-se dizer que o nazismo e seus crimes estão muito mais presentes no debate público e na memória coletiva hoje em dia do que após a Guerra. As tentativas feitas nos anos 1980 
por certos historiadores conservadores, como Ernst Nolte, para virar definitivamente a página do nazismo em nome de uma "normalização" da história alemã, tiveram o efeito totalmente contrário e suscitaram calorosos debates, tanto entre os historiadores quanto por parte da opinião pública ${ }^{18}$. Ainda recentemente, o extraordinário sucesso, na Alemanha, do livro de Daniel Goldhagen, contestável e contestado no plano científico, Os Carrascos Voluntários de Hitler, e os debates que ele provocou, mostram que esse passado criminoso e trágico permanece presente nas consciências ${ }^{19}$.

\section{Alemanha e Argentina: elementos de comparação}

A reflexão de Jaspers acerca da Alemanha oferece elementos úteis para uma análise da situação argentina após a última ditadura? Comecemos relembrando algumas analogias e diferenças entre a Alemanha nazista e a Argentina de Videla. A principal analogia reside no fato de que, em ambos os casos, há um terrorismo de Estado. A Argentina também experimentou, durante a ditadura, o "duplo Estado" 20 de que fala Ernst Fraenckel acerca da Alemanha nazista: de um lado, um Estado "normal", por assim dizer, regido por normas jurídicas e baseado no direito; do outro, um Estado terrorista, que não respeitava nenhuma norma jurídica e onde a arbitrariedade e a violência não conheciam limites. Nos dois casos, o terror era prioritariamente dirigido contra certos setores da sociedade considerados como inimigos pelo regime, mas visava ao mesmo tempo a impor o silêncio e "disciplinar" o conjunto do corpo social, após tê-lo atomizado. Em contrapartida, uma importante diferença consiste no fato de que a violência da ditadura argentina se voltava quase exclusivamente contra a população do próprio país, ao passo que a violência nazista se dirigia a certos setores da população alemã e, ao mesmo tempo, ao exterior, e que foi principalmente fora de suas fronteiras que ela provocou o maior número de vítimas. Refinando a análise, pode-se observar que essa violência era muito mais codificada e regulamentada na Alemanha do que na Argentina. Neste país, uma pessoa podia "desaparecer" mesmo sem nenhuma razão política; simplesmente, por exemplo, porque alguns agentes do Estado terrorista haviam 
Reflexões sobre os conceitos de responsabilidade e culpa...

decidido ficar com seus bens. A ideia, propriamente diabólica, de roubar os filhos das pessoas assassinadas, para depois confiá-los aos assassinos, foi também uma especificidade argentina que os nazistas não haviam imaginado.

Em nenhum momento, o regime militar argentino beneficiouse de um consenso popular comparável ao do regime nazista, mesmo que no início tenha sido recebido com alívio por muitas pessoas que esperavam simplesmente um restabelecimento da ordem após o caos dos anos de governo de Isabel Perón. Todavia, ele contou com o apoio de diferentes grupos sociais e instituições (a hierarquia da Igreja católica, por exemplo, ou o patronato), e com a indiferença e o espírito de submissão de uma parte da população, convencida de que deveria haver uma razão ("por algo será") para se prender algumas pessoas.

A exploração do nacionalismo e do patriotismo como instrumentos de legitimação e de manipulação também foi comum ao regime nazista e à Junta argentina. Os dois regimes deram provas do mesmo desprezo pela vida humana e do mesmo sadismo na tortura e na destruição das pessoas. A técnica do desaparecimento de pessoas, principal instrumento do arsenal de terror da Junta, não deixa de lembrar a operação "Noite e Nevoeiro"21 dos nazistas, do mesmo modo que os centros de detenção clandestina e de tortura na Argentina evocam, sob vários aspectos, os campos de concentração e de extermínio nazistas. Os dois regimes são culpados por violações maciças e sistemáticas dos direitos humanos e, mais particularmente, por crimes contra a humanidade. Essas analogias, que não são secundárias, justificam uma abordagem comparativa, desde que não se esqueça, naturalmente, as importantes diferenças entre os dois casos.

Procedendo por ordem, pode-se observar, inicialmente, acerca da culpa criminal que a impunidade concedida na Argentina pelas leis da anistia (Punto Final y Obediencia Debida) e pelo indulto presidencial a todos os responsáveis por crimes cometidos durante a ditadura constitui o equivalente ao que teria sido, na Alemanha do pós-Guerra, uma anistia geral a todos os criminosos nazistas: ideia impensável naquele momento. $\mathrm{Na}$ Argentina, o próprio princípio de justiça foi ultrajado, com consequências graves e duradouras 
para toda a sociedade. Como se poderia, de fato, respeitar uma lei e uma justiça que condenam severamente um ladrão menor quando deixam em liberdade os autores de crimes contra a humanidade? Quanto às forças armadas enquanto instituição, elas não podem mais pretender o respeito da sociedade após as leis de anistia que impuseram. O processo e a condenação dos membros da Junta Militar havia permitido distinguir entre os principais responsáveis pelo terrorismo de Estado e o restante da instituição militar, mais ou menos como o julgamento de Nuremberg, logo após a Segunda Guerra Mundial, permitira distinguir entre os chefes nazistas e o restante da população. A única maneira de evitar que os militares argentinos fossem considerados todos responsáveis pelos crimes da ditadura teria sido levar à justiça e condenar aqueles que, individualmente, eram culpados por crimes: isso teria permitido inocentar os outros. As leis de anistia tornaram impossível essa distinção, que só podia ser feita pelos tribunais: consequentemente, as forças armadas, enquanto instituição, são inevitavelmente percebidas em sua totalidade como criminosas. A reflexão de Karl Jaspers - "A fórmula 'uma ordem é uma ordem' [...] jamais pode ter valor decisivo. Um crime continua sendo um crime mesmo que tenha sido ordenado" (JASPERS, 1990, p. 46) - aplica-se perfeitamente ao caso argentino, em particular à lei de Obediencia Debida.

Do ponto de vista da responsabilidade política, o fato de que os militares tenham tomado o poder por meio de um golpe de Estado constitui uma situação muito diferente daquela da Alemanha, onde milhões de eleitores haviam votado em Hitler. No caso argentino, é preciso se questionar sobre as responsabilidades diretas de ambos os lados na engrenagem que culminou na instauração da ditadura, assim como sobre a responsabilidade das pessoas e dos grupos que a apoiaram. Esse exame de consciência só foi feito parcialmente. Seria ainda mais importante que a sociedade argentina se interrogasse sobre as condições que tornaram possível a transformação de uma quantidade tão grande de pessoas (essencialmente militares e policiais) em torturadores e criminosos. De fato, aqueles que cometeram esses crimes horríveis não eram monstros, mas homens comuns em geral, que uma determinada educação e formação prepararam para agir assim: em outras palavras, os agentes do terrorismo de Estado 
eram um produto da sociedade argentina e da educação que haviam recebido. $\mathrm{O}$ exame de consciência político e histórico não pode, pois, deter-se no curto período da ditadura, mas deve se estender, como sugerira Jaspers para a Alemanha, à geração dos pais, para tentar compreender as origens da violência.

Do mesmo modo que na Alemanha nazista, também na Argentina, uma parte da sociedade optou deliberadamente por ignorar o que se passava à sua frente ou ao lado. Ela tentou viver "normalmente", negando a realidade do terror ou agindo como se ele não existisse: é esta singular coexistência de normalidade e de terror que caracterizava este país na época da ditadura. Essa parcela da população criou para si um muro de separação protetor, que continua a condicionar sua memória da ditadura. Como salientou Primo Levi,

[...] o melhor meio de se defender da invasão de lembranças penosas é impedir sua entrada, levantar um cordão sanitário ao longo da fronteira. É mais fácil impedir uma lembrança de entrar do que se livrar dela depois que tiver sido gravada (LEVI, 1989, p. 31).

Essa parcela da população não deseja, evidentemente, questionar-se sobre o que aconteceu, e preferiria que se parasse de remexer nesse passado, virando definitivamente a página. Por outro lado, aqueles que cometeram crimes ou que foram cúmplices desejam igualmente que se faça silêncio sobre o passado, para não ter que enfrentar a questão de sua própria responsabilidade. Lembrar-se de um episódio ou de uma experiência traumáticos nunca é fácil, nem para a vítima nem para o culpado. Como observa ainda Primo Levi:

[...] a lembrança de um trauma, sofrido ou infligido, é ela própria traumatizante, porque sua rememoração faz sofrer ou, pelo menos, perturba; aquele que foi ferido tende a eliminar da sua consciência a lembrança para não renovar a dor; aquele que feriu empurra a lembrança para as profundezas de si a fim de se livrar dela, de atenuar seu sentimento de culpa (LEVI, 1989, p. 24). 
Porém, aqueles que foram vítimas, mesmo quando se fecham no silêncio, não conseguem esquecer, ainda que o desejem. Assim, encontram-se, na Argentina, comportamentos similares aos observados na Alemanha após a Guerra que foram objeto da reflexão de Jaspers: uma parte da sociedade não quer se lembrar, enquanto a outra não consegue esquecer. A “teoria dos dois demônios" traduz a aspiração de uma parcela considerável da sociedade argentina a evitar se debruçar seriamente sobre seu passado e sobre suas responsabilidades. Tanto os militares quanto os membros das organizações armadas são considerados responsáveis pela eclosão da violência. Nessa teoria, cuja evidente fragilidade consiste no fato de colocar no mesmo plano o terrorismo de Estado e o da guerrilha, o elemento essencial é a palavra "demônios". Por definição, os "demônios" não são homens, mas algo estranho e inexplicável: propor falar dos "demônios" significa, portanto, renunciar a se interrogar sobre as causas e as circunstâncias que transformaram homens comuns em torturadores e carrascos e sobre os mecanismos sociais e psicológicos que produziram tais "demônios".

\section{Considerações finais}

O exemplo de Jaspers mostra que uma reflexão crítica pode permanecer isolada por muito tempo, mas que é impossível eliminar da consciência indefinidamente o passado. $\mathrm{Na}$ Alemanha ocidental, os problemas discutidos em $A$ culpa alemã encontraram-se novamente no centro do debate público a partir dos anos 1960, e a confrontação com o passado nazista continua até hoje. O debate deslocou-se em parte e novas questões surgiram, ao passo que outras, como a do Holocausto, por exemplo, assumiram uma posição central. Cada nova geração lança um novo olhar sobre o passado e constrói sua identidade por meio de um trabalho de memória, sempre renovado, em função das preocupações do presente. $\mathrm{O}$ mesmo acontece na Alemanha e na Argentina: o passado traumático está sempre presente, o esquecimento revela-se impossível, mas o trabalho de memória, como a tela de Penélope, precisa ser recomeçado sempre. Desse trabalho depende o estado de saúde democrática de uma 
Reflexões sobre os conceitos de responsabilidade e culpa...

sociedade. Uma Alemanha que esquecesse o passado nazista e seus crimes seria profundamente inquietante. O mesmo aconteceria com a Argentina, se o esquecimento e a impunidade conseguissem vencer definitivamente.

\section{REFLECTIONS ON THE CONCEPTS OF RESPONSIBILITY} AND CULPABILITY IN KARL JASPERS AND ON THEIR APPLICABILITY TO THE ARGENTINIAN DICTATORSHIP OF 1976-1983

Abstract: The first part of this article analizes the concepts of responsability and culpability, developed by the German philosopher Karl Jaspers in 1946 in his book Die deutsche Schuld (The German culpability) concerning Nazy Germany's crimes. He invited his compatriots to an examination of conscience on these problems, but his voice remained isolated in a society whose main aspiration was to forget the Nazi past. Since the Sixties, however, the Federal Republic started a memory work that is still going on. The second part of the article discusses the possibility of applying Jaspers's concepts to the Argentinian society during and after the dictatorship of 1976-1983.

Keywords: Nazism. Jaspers. Culpability. Memory. Argentina.

\section{Notas}

${ }^{1}$ JASPERS, Karl. La culpabilité allemande. Paris: Les Editions de Minuit, 1990 (alemão, Die Schuldfrage, 1946). Minhas citações fazem referência a essa edição francesa. Há também uma tradução espanhola recente: Elproblema de la culpa. Sobre la responsabilidad politica de Alemania. Barcelona/Buenos Aires/México: Paidós, 1998. ${ }^{2}$ Karl Jaspers escrevia em 1946: "Vivemos essa situação surpreendente: apesar de todo o mal, a identificação com o exército e com o Estado continuou. Esse valor absoluto atribuído a uma concepção cegamente nacional [...] fazia com que, mesmo tendo a consciência limpa, se era moralmente culpado". JASPERS, op. cit., p. 75. 3 "Vivimos en la penuria, incluso una gran parte de nuestra población vive en una penuria tan grande, tan inmediata, que parece haberse vuelto insensible para tales controversias. A ellos les interesa lo que puede remediarla penuria, lo que puede proporcionar trabajo y pan, vivienda y calefacción. El horizonte se ha estrechado. No se quiere oír hablar de culpa, del pasado, uno no se encuentra afectado por la historia universal. Se quiere dejar simplemente de sufrir, salir de la miseria, vivir, pero no reflexionar. Se trata sobre todo de un estado de ánimo tal como si después de un sufrimiento tan espantoso se tuviera que ser en cierto 


\section{Bruno Groppo}

modo recompensado, consolado en todo caso, pero no se pudiera cargar encima con la culpa". JASPERS, op. cit., p. 50 da edição espanhola.

4 "Nosotros los alemanes estamos obligados sin excepción a abordar con claridad el asunto de nuestra culpa y extraer las consecuencias pertinentes. Nuestra dignidad humana nos obliga. No puede resultarnos indiferente lo que en mundo piense de nosotros, pues nos sabemos formando parte de la humanidad, somos en primer lugar hombres y después alemanes. Pero aún más importantes para nosotros que nuestra propia vida en la penuria y la dependencia pueda tener aún dignidad gracias a la veracidad frente a nosotros mismos. La cuestión de la culpa, más que una pregunta que nos formulan los demás, es una pregunta que nosotros nos formulamos. La respuesta que le demos en lo más íntimo fundamentará nuestra actual conciencia de lo que es y de lo propio. Es una cuestión de vida o de muerte para el alma alemana". JASPERS, op. cit., p. 51 da edição espanhola. 5 "Um Estado criminoso pesa moralmente sobre o povo inteiro", escreve ele. JASPERS, op. cit., p. 64.

6 "La destrucción de todo orden político alemán decente y verdadero tiene su fundamento también en el modo de comportarse de la mayoría de la población alemana. Un pueblo responde por su vida política". JASPERS, op. cit., p. 80 da edição espanhola.

7 “Tenemos que responder nosotros los alemanes por las atrocidades que hemos sufrido por parte de alemanes o por aquéllas otras de las que nos hemos librado milagrosamente? Sí, en tanto que hemos tolerado el surgimiento de un régimen tal entre nosotros. No, en tanto mucho de nosotros en nuestro fuero interno éramos contrarios a toda esa maldad, por lo que no tenemos que reconocer en nuestro interios complicidad moral por ningún acto o motivación. Hacer responsable a alguien no significa declararle moralmente culpable". JASPERS, op. cit., p. 80 da edição espanhola.

8 "Hay una solidaridad entre hombres como tales que hace a cada uno responsable de todo el agravio y de toda la injusticia del mundo, especialmente de los crímenes que suceden en su presencia o con su conocimiento". JASPERS, op. cit., p. 54 da edição espanhola.

${ }^{9}$ Cf. KOEBNER, Thomas, 1987. Die Schuldfrage. Vergangenheitsverweigerung und Lebenslïgen in der Diskussion 1945-1949.

${ }^{10}$ Ver o estudo de FREI, Norbert, 1999. Vergangenheitspolitik. Die Anfänge der Bundesrepublik und die NS-Vergangenheit.

${ }^{11} \mathrm{O}$ trecho entre colchetes e em itálico trata-se de informação inserida pelo autor.

${ }^{12}$ Ver também MITSCHERLICH, Alexander et Margarete, Le denil impossible, Paris, Payot, 1972 (alemão, Die Unfäbigkeit zu trauern. Grundlagen kollektiven Verbaltens, Munich, Piper and Co., 1967).

${ }^{13}$ De BENZ, 1994, ver, particularmente, a p. 24. Ver também GIORDANO, op. cit. 


\section{Reflexões sobre os conceitos de responsabilidade e culpa...}

${ }^{14}$ Em um trabalho publicado vinte anos após o lançamento deste livro, Margarethe Mitscherlich constatava que esse trabalho de confrontação com o nazismo não estava acabado: "Mesmo aqueles com 20 anos hoje e que herdaram de seus pais as defesas que estes haviam levantado contra o passado, mesmo estes continuam a viver à sombra da denegação e do recalcamento de acontecimentos que não podem ser resolvidos apenas pelo esquecimento”. Ver MITSCHERLICH, 1987, p. 114. ${ }^{15}$ Ver também REICHEL, Peter. L'Allemagne et sa mémoire, Paris, Odile Jacob, 1998. ${ }^{16}$ Também GIORDANO, op. cit., p. 205-214.

${ }^{17}$ A obra já citada de Alexander e Margarete Mitscherlich, publicada em 1967, teve muita importância desse ponto de vista. Como observa ROBIN, Régine, op. cit., p. 45: "[...] ela possibilita a toda uma geração pensar o silêncio dos pais diante do acontecimento traumático de que todos mais ou menos tomaram parte e vai marcar a cultura alemã até aos questionamentos dos anos 1980”. Sobre o tema da ruptura entre gerações, ver também GAUDARD, Pierre-Yves, op. cit.

${ }^{18}$ Cf. Devant l'bistoire. Les documents de la controverse sur la singularité de l'extermination des Juifs par le régime nazi, Paris, Cerf, 1988.

${ }^{19}$ GOLDHAGEN, Daniel, Les bourreaux volontaires de Hitler, Paris, Seuil, 1997. [Os Carrascos Voluntários de Hitler - O povo alemão e o Holocausto. São Paulo, Cia das Letras, 1997]. Sobre as controvérsias suscitadas pelo livro de Goldhagen, ver HUSSON, Edouard. Une culpabilité ordinaire? Hitler, les Allemands et la Shoah. Les enjeux de la controverse Goldhagen, Paris, F. de Guibert, 1997. Na Itália, o livro de Goldhagen suscitou pouco interesse.

${ }^{20}$ Retomo aqui a fórmula de FRAENKEL, Ernst, 1983 (1ª ed. 1941). Fraenkel utiliza a categoria do "duplo Estado" para indicar "a presença simultânea, no Terceiro Reich, de um 'Estado normativo', que funciona respeitando em geral suas próprias leis, e de um 'Estado discricionário', que, ao contrário, age ignorando essas mesmas leis, enquanto sistema de dominação, da arbitrariedade absoluta e da violência. O ‘duplo Estado’ caracteriza-se, portanto, pela coexistência de um sistema jurídico positivo e de uma ausência total de direito, em virtude da qual o regime nazista se reservou de suspender o direito positivo em todas as questões consideradas como 'políticas' e de substituí-lo por medidas arbitrárias” (Essa passagem figura na quarta capa do livro). O conceito elaborado por Fraenkel pode ser aplicado de modo útil, parece-me, à análise da ditadura militar argentina. Outra chave de leitura útil parece o conceito de "compromisso autoritário" aplicado pelo historiador suíço Philippe Burrin à análise das ditaduras nazista e fascista para designar a aliança informal feita com as forças conservadoras. Cf. BURRIN, Philippe. Fascisme, nazisme, autoritarisme. Paris: Seuil, 2000. p. 15-22.

${ }^{21}$ Nacht und Nebel, em alemão: código para as operações em que pessoas foram eliminadas sem deixar vestígios. (N.de T.). 


\section{Bruno Groppo}

\section{Referências}

BENZ, Wolfgang. Nachkriegsgesellschaft und Nationalsozialismus. Erinnerung, Amnesie, Abwehr. In: BENZ, Wolfgang; DISTEL, Barbara (hg. Von). Erinnern oder Verweigern. Das schwierige Thema Nationalsozialismus. München: DTV, 1994. p. 12-24. BURRIN, Philippe. Fascisme, nazisme, autoritarisme. Paris: Seuil, 2000.

DEVANT L'HISTOIRE. Les documents de la controverse sur la singularité de l'extermination des Juifs par le régime nazi. Paris: Cerf, 1988.

FRAENKEL, Ernst. Il doppio Stato. Contributo alla teoria della dittatura. Milan: Einaudi, 1983 (primeira ed. The Dual State. A Contribution to the Theory of Dictatorship, New York/London/Toronto: Oxford University Press 1941).

FREI, Norbert. Vergangenheitspolitik. Die Anfänge der Bundesrepublike und die NSVergangenheit. Muchich: Deutscher Taschenbuch Verlag, 1999.

GAUDARD, Pierre-Yves. Le fardean de la mémoire. Paris: Plon, 1997.

GIORDANO, Ralph. Die zweite Schuld, oder von der Last, Deutscher zu sein. München: Knaur, 1990.

GOLDHAGEN, Daniel. Les bourreaux volontaires de Hitter. Paris: Seuil, 1997.

HUSSON, Edouard. Une culpabilité ordinaire? Hitler, les Allemands et la Shoah. Les enjeux de la controverse Goldhagen. Paris: F. de Guibert, 1997.

JASPERS, Karl. La culpabilité allemande. Paris: Les Editions de Minuit, 1990 (Primeira ed. al. Die Schuldfrage. Heidelberg/Zürich 1946)

KOEBNER, Thomas. Die Schuldfrage. Vergangenheitsverweigerung und Lebenslügen in der Diskussion 1945-1949. In: KOEBNER, Thomas; SAUTERMEISTER, Gart; SCHNEIDER, Sigrid (Dir.). Deutschland nach Hitler. Opladen, 1987. p. 301-329.

LEVI, Primo. Les naufragés et les rescapés. Quarante ans après Auschwitz. Paris: Gallimard, 1989.

MITSCHERLICH, Alexander; MITSCHERLICH, Margarete. Le denil impossible. Paris: Payot, 1972 (Primeira ed. al. Die Unfäbigkeit ₹u trauern. Grundlagen kollektiven Verhaltens, München: R. Piper \& Co., 1967).

MITSCHERLICH Margarete. Erinnerungsarbeit:Zur Psychoanalyse der Unfähigkeit zu trauern. Frankfurt am Main: Fischer, 1987.

REICHEL, Peter. L'Allemagne et sa mémoire. Paris: Odile Jacob, 1998 (Primeira ed. al. Politik mit der Erinnerung. Gedächtnisorte im Streit um die nationalsozialistische Vergangenheit. Hanser, München, 1995). 
Reflexões sobre os conceitos de responsabilidade e culpa...

.Vergangenheitsbewältigung in Deutschland. Die Auseinandersetzung mit der NSDiktatur von 1945 bis heute. C.H.Beck Verlag, München, 2001.

ROBIN, Régine. Berlin chantiers. Essai sur les passés fragiles. Paris: Stock, 2001.

SCHWAN, Gesine. Politik und Schuld. Die zerstörerische Macht des Schweigens. Frankfurt am Main: Fischer Taschenbuchverlag, 1997.

Recebido em: 02/09/2012

Aprovado em: 02/10/2012 